\title{
The Salmonella SPI-2 effector SseJ exhibits eukaryotic activator-dependent phospholipase A and glycerophospholipid : cholesterol acyltransferase activity
}

\author{
Nadine S. Lossi, ${ }^{1}$ Nathalie Rolhion, ${ }^{1}$ Anthony I. Magee, ${ }^{2}$ Cliona Boyle ${ }^{1}$ \\ and David W. Holden ${ }^{1}$ \\ ${ }^{1}$ Centre for Molecular Microbiology and Infection, Imperial College London, Armstrong Road, \\ London SW7 2AZ, UK
}

Correspondence

d.holden@imperial.ac.uk

Received 2 April 2008

Revised 16 May 2008

Accepted 28 May 2008

\begin{abstract}
Intracellular replication of Salmonella enterica serovar Typhimurium within membrane-bound compartments, called Salmonella-containing vacuoles, depends on the activities of several effector proteins translocated by the Salmonella pathogenicity island 2 (SPI-2)-encoded type III secretion system. The SPI-2 effector protein SseJ shows similarity at the amino acid level to several GDSL lipases with glycerophospholipid : cholesterol acyltransferase (GCAT) activity. In this study, we show that catalytic serine-dependent phospholipase A (PLA) and GCAT activity of recombinant SseJ is potentiated by factor(s) present in HeLa cells, RAW macrophages and Saccharomyces cerevisiae. SseJ activity was enhanced with increasing amounts of, or preincubation with, eukaryotic cell extracts. Analysis of the activating factor(s) shows that it is soluble and heat- and protease-sensitive. We conclude that PLA and GCAT activities of SseJ are potentiated by proteinaceous eukaryotic factor(s).
\end{abstract}

\section{INTRODUCTION}

Salmonella enterica serovar Typhimurium (S. Typhimurium) invades a variety of host cell types and replicates intracellularly within a membrane-bound compartment, the Salmonellacontaining vacuole (SCV). Numerous Salmonella virulence genes are required for growth of this pathogen in mice; several of these are associated with the Salmonella pathogenicity island 2 (SPI-2) type III secretion system (T3SS). This is expressed upon bacterial entry into host cells and translocates a variety of effector proteins across the SCV into the host cell (Cirillo et al., 1998; Waterman \& Holden, 2003). A functional SPI-2 T3SS is essential for intracellular survival and systemic growth of Salmonella in mice (Hensel et al., 1995; Ochman et al., 1996). Approximately 20 SPI-2 effectors have been identified to date, but their molecular functions remain largely unknown (Haraga et al., 2008; Waterman \& Holden, 2003).

The effector protein SseJ is encoded outside SPI-2, but translocated via the SPI-2 T3SS (Miao \& Miller, 2000).

Abbreviations: CE, cholesterol ester; DPPC, 1,2-dipalmitoylphosphatidylcholine; FFA, free fatty acids; GCAT, glycerophospholipid : cholesterol acyltransferase; GST, glutathione-S-transferase; 1-MPLPC, 1-monopalmitoyllysophosphatidylcholine; PLA, phospholipase A; PLA2, phospholipase A2; PNPB, para-nitrophenyl butyrate; PNS, postnuclear supernatant; SCV, Salmonella-containing vacuole; SPI-2, Salmonella pathogenicity island 2; T3SS, type III secretion system.
Interestingly, deletion of sseJ does not have a detectable effect on replication of $S$. Typhimurium in epithelial cells or macrophage-like cell lines, but results in a mild replication defect in elicited peritoneal macrophages (Ruiz-Albert et al., 2002) and reduced virulence after intraperitoneal inoculation of BALB/c mice (Freeman et al., 2003; Ruiz-Albert et al., 2002). SseJ has been linked functionally to SifA by virtue of the phenotype of a sifA sseJ double mutant (Ruiz-Albert et al., 2002). SifA is a SPI-2 T3SS effector required for the formation of tubules (called Sifs) that extend from SCVs in epithelial cells (Stein et al., 1996). sifA mutants fail to make Sifs and gradually lose their vacuolar membrane (Beuzon et al., 2000). However, the process of vacuolar membrane loss is significantly delayed in a sifA sseJ double mutant (Ohlson et al., 2005; Ruiz-Albert et al., 2002), suggesting that SseJ may help to destabilize the SCV membrane around the sifA mutant. Furthermore, deletion of sseJ has been shown to result in increased levels of Sifs (Birmingham et al., 2005). Therefore, SseJ appears to oppose the activity of SifA.

The N-terminal domain of SseJ contains a translocation signal also found in some other SPI-2 effector proteins: SspH1, SspH2, SlrP, SifA, SifB and SseI (Miao \& Miller, 2000). The C-terminal region (amino acids 140-408) is $29 \%$ identical to several members of the GDSL lipase family, with highest similarity at the amino acid sequence 
level to a glycerophospholipid: cholesterol acyltransferase (GCAT) found in Aeromonas hydrophila (Brumlik \& Buckley, 1996; Miao \& Miller, 2000). Members of the GDSL family of lipases are characterized by the presence of a conserved GDSL motif and a catalytic triad (S-D-H) (Akoh et al., 2004; Upton \& Buckley, 1995). Mutation of residues of the catalytic triad causes loss of lipolytic and acyltransferase activity (Brumlik \& Buckley, 1996). Alignment of SseJ with GCAT (Flieger et al., 2002) reveals the presence of a GDSL motif as well as the conserved catalytic triad (S151, D274, H384). In agreement with these predicted catalytic residues, recent studies have shown that the virulence attenuation of $\Delta s s e J$ in mice cannot be rescued by expression of $\mathrm{SseJ}_{\mathrm{S} 151 \mathrm{~A}}$, SseJ $\mathrm{J}_{\mathrm{D} 274 \mathrm{~N}}$ or $\mathrm{SseJ}_{\mathrm{H} 384 \mathrm{~N}}$, indicating that these residues are important for function of SseJ in vivo (Ohlson et al., 2005). In vitro, S151, D247 and H384 have been shown to be necessary for deacylase activity of recombinant SseJ (Ohlson et al., 2005), supporting the notion that these represent a catalytic triad similar to those of other GDSL lipases (Ohlson et al., 2005). Recently, SseJ has been shown to esterify cholesterol in vitro, in HeLa cells and macrophages (Nawabi et al., 2008).

In this study, we analysed the biochemical activity of SseJ. We show that SseJ exhibits phospholipase A (PLA) and GCAT activity and that both enzymic activities require the presence of a eukaryotic activator.

\section{METHODS}

Bacterial strains and growth conditions. Escherichia coli was grown in Luria-Bertani (LB) medium supplemented with carbenicillin $\left(50 \mu \mathrm{g} \mathrm{ml}^{-1}\right)$ when appropriate. Saccharomyces cerevisiae AH 109 was grown in YPD medium supplemented with $20 \mathrm{mg} \mathrm{l}^{-1}$ adenine hemisulfate (YPDA). Strains used in this study are summarized in Table 1.

Reagents. Lipofectamine 2000 transfection reagent was purchased from Invitrogen. 1,2-Dipalmitoylphosphatidylcholine (DPPC) and 1monopalmitoyllysophosphatidylcholine (1-MPLPC) were purchased from Avanti Polar Lipids. Cholesterol and cholesteryl oleate, paranitrophenyl butyrate (PNPB), esterase from porcine liver, phospholipase A2 (PLA2) from porcine liver and protease inhibitors (aprotinin, leupeptin, pepstatin A) were obtained from Sigma. $\left[{ }^{3} \mathrm{H}\right]$ cholesterol (specific activity $40 \mathrm{Ci} \mathrm{mmol}{ }^{-1} ; 1.5 \mathrm{TBq}^{\mathrm{mmol}}{ }^{-1}$ ) was purchased from American Radiolabelled Chemicals.
Cell culture. HeLa (93021013) and RAW 264.7 (91962702) cells were obtained from the European Collection of Cell Cultures, Salisbury, UK, and grown in Dulbecco's modified Eagle's medium (DMEM) supplemented with $10 \%$ fetal calf serum (FCS) and $2 \mathrm{mM}$ glutamine at $37{ }^{\circ} \mathrm{C}$ in $5 \% \mathrm{CO}_{2}$.

Plasmids. Expression plasmids pmyc: : sseJ and pmyc: :sseJ $J_{\mathrm{S} 151 \mathrm{~V}}$ have been described previously (Ruiz-Albert et al., 2002). pmyc::sseJ expresses a full-length version of SseJ bearing an $\mathrm{N}$-terminal fusion to the c-myc epitope tag in pRK5-myc (Lamarche et al., 1996). pmyc:: $s s e J_{S 151 V}$ expresses a catalytically inactive SseJ $_{S 151 V}$ bearing an $\mathrm{N}$-terminal fusion to the c-myc epitope tag. pGEX4T2:: sseJ was used for expression of GST-SseJ. This plasmid (kindly provided by Dr Stéphane Méresse, Centre d'Immunologie de Marseille-Luminy, France) contains sseJ under the control of an IPTG-inducible promoter. The plasmid pGEX4T2::sseJ $J_{\mathrm{mt}}$ was constructed by sitedirected mutagenesis of pGEX4T2:: sseJ, using the primers sseJ-1 ( $5^{\prime}-$ TTTTGGCGACGTCTTGTCTGACTCC-3') and sseJ-2 (5' -CCATAAAAAACCGCTGCAGAACAGACTG-3') and $P f u$ Ultra-high-fidelity polymerase (Stratagene). pGEX4T2:: sseJ $J_{\mathrm{mt}}$ expresses a catalytically inactive version of full-length SseJ, in which $S$ in position 151 is replaced by $\mathrm{V}$, fused to the $\mathrm{C}$ terminus of glutathione- $S$-transferase (GST). All constructs were verified by DNA sequencing prior to use. Plasmids used in this study are summarized in Table 1.

Transfection. HeLa cells $\left(5 \times 10^{5}\right)$ were seeded in six-well plates $24 \mathrm{~h}$ prior to transfection with lipofectamine 2000 transfection reagent according to the manufacturer's manual (Invitrogen).

GST protein purification. Expression of GST fusion proteins was induced with $0.5 \mathrm{mM}$ IPTG (Sigma) in E. coli BL21 (DE3) (Amersham Biosciences) at $25{ }^{\circ} \mathrm{C}$ for $4 \mathrm{~h}$ prior to collection of cell pellets by centrifugation. Cells were resuspended in $40 \mathrm{mM}$ Tris, pH 7.4, containing Complete protease inhibitor cocktail (Roche) and subsequently lysed by passage through a French Press. The soluble fraction was isolated by ultracentrifugation at $130000 \mathrm{~g}$ and subsequently incubated with glutathione-Sepharose beads (Amersham Biosciences) for $2 \mathrm{~h}$ at $4{ }^{\circ} \mathrm{C}$. Beads were washed with PBS and $40 \mathrm{mM}$ Tris, $100 \mathrm{mM} \mathrm{NaCl}, \mathrm{pH} 8.0$, before fusion proteins were eluted using $10 \mathrm{mM}$ glutathione (Sigma), dialysed in $40 \mathrm{mM}$ Tris, $\mathrm{pH}$ 7.4, and concentrated before use using Amicon-10 filter devices (Millipore).

Cell extracts. HeLa and RAW 264.7 cells were grown in $175 \mathrm{~cm}^{2}$ dishes to $80 \%$ confluence, scraped into ice-cold PBS, pelleted at $200 \mathrm{~g}$ for $5 \mathrm{~min}$ and resuspended in homogenization buffer [8.5\% sucrose (w/v), $3 \mathrm{mM}$ imidazole]. HeLa cells were broken by passage through a $22 \mathrm{G}$ needle; RAW 264.7 cells were broken by passage through a $27 \mathrm{G}$ needle. Postnuclear supernatant (PNS) was obtained after centrifugation at $1500 \mathrm{~g}$ for $5 \mathrm{~min}$ at $4{ }^{\circ} \mathrm{C}$. Membranes and cytosol fractions

Table 1. Strains and plasmids used in this study

\begin{tabular}{|c|c|c|}
\hline Strain & Description & Reference/source \\
\hline Sacc. cerevisiae AH 109 & Sacc. cerevisiae & BD Biosciences, Clontech \\
\hline E. coli BL21 (DE3) & E. coli BL21 (DE3) & Amersham Biosciences \\
\hline S. Typhimurium 12023 & Wild-type $S$. Typhimurium & NTCC (Colindale, UK) \\
\hline pGEX4T-2 & Vector containing gene encoding GST & Amersham Biosciences \\
\hline pGEX4T2:: sseJ & Vector expressing GST-SseJ & This study \\
\hline pGEX4T2: : sse J $J_{\mathrm{mt}}$ & Vector expressing GST-SseJS151V & This study \\
\hline $\mathrm{p} m y c:: s s e J$ & pRK5myc: :sseJ & Ruiz-Albert et al. (2002) \\
\hline $\mathrm{p} m y c:: s s e J_{\mathrm{S} 151 \mathrm{~V}}$ & pRK5myc: : sseJ $J_{\mathrm{S} 151 \mathrm{~V}}$ & Ruiz-Albert et al. (2002) \\
\hline
\end{tabular}


of HeLa cells were separated by ultracentrifugation at $100000 \mathrm{~g}$ for $1 \mathrm{~h}$. Where indicated, HeLa cell cytosol was further treated by incubation with $250 \mu \mathrm{g}$ trypsin $\mathrm{ml}^{-1}$ for $15 \mathrm{~min}$ at $30^{\circ} \mathrm{C}$, followed by addition of the trypsin inhibitor aprotinin. For preparation of Sacc. cerevisiae cell extract, Sacc. cerevisiae AH109 was grown overnight in YPDA medium at $30{ }^{\circ} \mathrm{C}$, and cells were resuspended in $50 \mathrm{mM}$ $\mathrm{Na}_{3} \mathrm{PO}_{4}$ buffer, $\mathrm{pH} 7.4$, supplemented with protease inhibitors $[10 \mu \mathrm{g}$ aprotinin $\mathrm{ml}^{-1}, 5 \mu \mathrm{g}$ leupeptin $\mathrm{ml}^{-1}, 1 \mu \mathrm{M}$ pepstatin $\mathrm{A}$ and Complete protease inhibitor cocktail (Roche)]. Cells were broken by four passages through a French Press and the soluble cell extract was obtained after pelleting of cell debris by centrifugation at $14000 \mathrm{~g}$ for $30 \mathrm{~min}$. E. coli BL21 soluble extract was prepared from an overnight

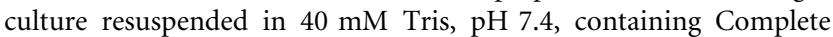
protease inhibitor cocktail (Roche) by passage through a French Press and subsequent ultracentrifugation at $130000 \mathrm{~g}$.

Deacylase assay. The PNPB deacylase assay was carried out as described elsewhere (Bonelli \& Jonas, 1989; Ohlson et al., 2005). Briefly, $5 \mu \mathrm{g}$ GST fusion protein was added to the assay reaction mix [1 ml containing $50 \mathrm{mM}$ PNPB, $20 \mathrm{mM}$ Tris, $\mathrm{pH} \mathrm{7.4}$, and $3 \%$ acetonitrile (v/v)] in a cuvette, and $A_{400}$ was monitored over $30 \mathrm{~min}$ at $37{ }^{\circ} \mathrm{C}$ (UV-VIS spectrophotometer, Shimadzu UK). As a positive control, porcine liver esterase (Sigma) was used.

Phospholipase assay. DPPC liposomes and 1-MPLPC micelles

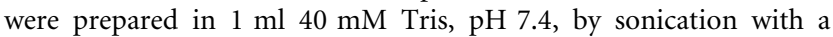
probe at a concentration of $13.4 \mathrm{mM}$. GST fusion proteins were preincubated with cell lysate for $1 \mathrm{~h}$ at $37{ }^{\circ} \mathrm{C}\left(30{ }^{\circ} \mathrm{C}\right.$ for yeast cell extract), where indicated. In general, $5 \mu \mathrm{g}$ GST fusion protein was incubated at $37^{\circ} \mathrm{C}$ at $\mathrm{pH} 7.4$ for $2 \mathrm{~h}$ with $3.35 \mathrm{mM}$ DPPC liposomes (3.35 mM 1-MPLPC micelles for lysophospholipase assay), with or without cell extract $(100 \mu \mathrm{l}$ if not otherwise stated; $7 \mathrm{mg}$ protein $\mathrm{ml}^{-1}$ ) in a final volume of $200 \mu \mathrm{l}$. Porcine liver PLA2 was used as a positive control in $40 \mathrm{mM}$ Tris, $\mathrm{pH}$ 7.4, supplemented with $10 \mathrm{mM}$ $\mathrm{CaCl}_{2}$. Free fatty acids (FFA) were quantified using a NEFA-C kit (Wako) according to the manufacturer's manual. To test whether superoxide dismutase (SOD-1) activates SseJ, $5 \mu \mathrm{g}$ GST fusion protein was pre-incubated with $20 \mu \mathrm{g}$ bovine SOD-1 (Sigma) in $150 \mu \mathrm{l} 40 \mathrm{mM}$ Tris, $\mathrm{pH} \mathrm{7.4}$, at $37^{\circ} \mathrm{C}$ for $1 \mathrm{~h}$ before addition of DPPC at a final concentration of $3.35 \mathrm{mM}$ and incubation for $2 \mathrm{~h}$ at $37{ }^{\circ} \mathrm{C}$.

Acyltransferase assay. Liposomes of equimolar amounts of DPPC and partially ${ }^{3} \mathrm{H}$-labelled cholesterol $(5 \mathrm{mM})$ were prepared in $20 \mathrm{mM}$ Tris, pH 7.4, $160 \mathrm{mM} \mathrm{KCl}$ and $1.4 \%$ (w/v) BSA by bath sonication for $30 \mathrm{~min}$. Liposomes $(50 \mu \mathrm{l})$ were incubated with $5 \mu \mathrm{g}$ GST fusion protein and $100 \mu \mathrm{l}$ eukaryotic cell lysate $\left(7 \mathrm{mg} \mathrm{ml}^{-1}\right)$ at $37{ }^{\circ} \mathrm{C}$ for $2 \mathrm{~h}$ in a final volume of $250 \mu \mathrm{l}$. The reaction was stopped by addition of $3 \mathrm{ml} \mathrm{CHCl}_{3}: \mathrm{MeOH}(1: 2, \mathrm{v} / \mathrm{v})$. Lipids were extracted by the method of Bligh \& Dyer (1959), and subsequently separated by TLC on glass-backed Silica 60 plates using petroleum ether: diethylether $(8: 2, \mathrm{v} / \mathrm{v})$. The cholesterol ester (CE) fractions were scraped into Betamax ES liquid scintillation fluid (MP Biomedicals) and d.p.m. were measured.

Statistical analysis. For analysis of the significance of differences between samples, Student's $t$ test was used. Differences denoted as significant in the text fall below a $P$ value of 0.05 .

\section{RESULTS}

\section{Lack of enzymic activity of recombinant SseJ in vitro}

To analyse the enzymic activity of SseJ in vitro, SseJ and SseJS151V were purified as GST fusion proteins (Fig. 1a) (a)

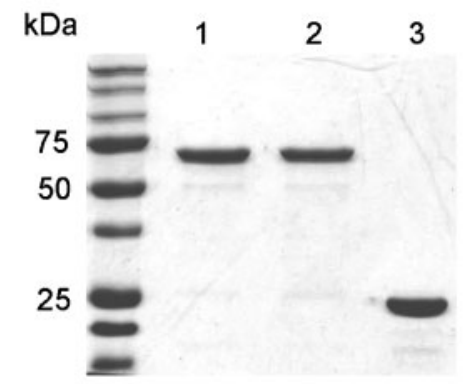

(b)

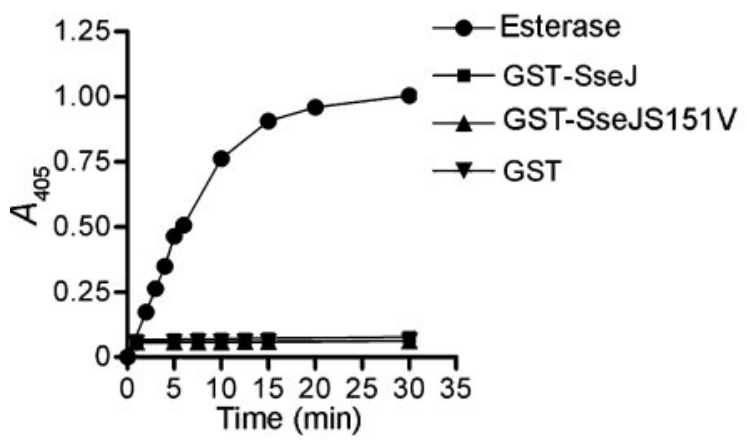

(c)

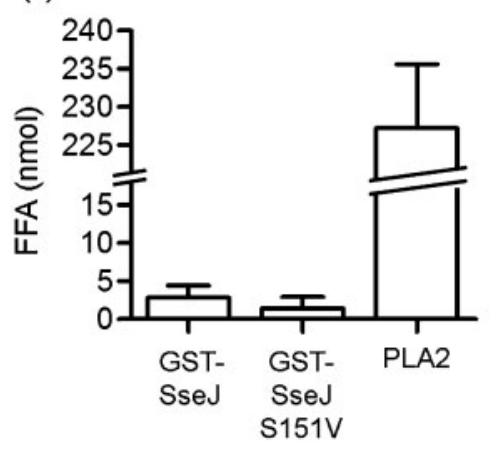

Fig. 1. SseJ does not display esterase or phospholipase activity in vitro. (a) Expression and purification of SseJ and SseJS151V as GST fusion proteins. Lanes: 1, purified GST-SseJ $(2 \mu \mathrm{g}) ; 2$, purified GST-SseJS151V $(2 \mu \mathrm{g}) ; 3$, purified GST $(2 \mu \mathrm{g})$. (b) GST-SseJ, GST-SseJS151V or GST was incubated with PNPB at $37^{\circ} \mathrm{C}, \mathrm{pH} 7.4$, while $A_{405}$ was monitored over $30 \mathrm{~min}$. Porcine liver esterase was used as a positive control. GST and GSTSseJS151V were used as negative controls. These data represent the mean from two independent experiments performed in triplicate. (c) GST-SseJ, GST-SseJS151V or GST was incubated with DPPC liposomes at $\mathrm{pH}$ 7.4. Released FFA were quantified after $2 \mathrm{~h}$ incubation at $37^{\circ} \mathrm{C}$. PLA2 from bovine pancreas functioned as a positive control. GST and GST-SseJS151V were used as negative controls. The value of FFA following incubation with GST alone was subtracted from values obtained after incubation of DPPC with GST-SseJ or GST-SseJS151V. These data represent the mean $\pm S D$ derived from three independent experiments performed in triplicate. 
and incubated with various substrates to test for esterase and PLA activity. As positive controls, porcine liver esterase was used to hydrolyse PNPB (Fig. 1b) and commercially available PLA2 was used to hydrolyse DPPC in liposomes (Fig. 1c). No enzymic activity was detected at $\mathrm{pH} 7.4$ when GST-SseJ was incubated with PNPB (Fig. 1b) or DPPC liposomes (Fig. 1c). Liposomes consisting of equimolar amounts of cholesterol and DPPC were also used to test whether SseJ displays acyltransferase activity in vitro, but no enzymic activity was detected (data not shown). To test whether the absence of detectable activity was due to the $25 \mathrm{kDa}$ GST tag at the $\mathrm{N}$ terminus of SseJ, the GST tag was cleaved from the purified protein, but no activity was detected (data not shown). SseJ and SseJS151V were also purified as polyhistidine fusion proteins, but neither had detectable enzymic activity under the assay conditions used (data not shown).

\section{SseJ displays PLA activity when expressed in HeLa cells}

Expression of SseJ following transfection of HeLa cells leads to the formation of globular membranous compartments (GMCs), which are dependent on the catalytic activity of SseJ (Ruiz-Albert et al., 2002). As enzymic activity of recombinant SseJ purified from E. coli was undetectable, we investigated its biochemical activity after expression in HeLa cells. HeLa cells were transfected with vectors expressing myc-SseJ or catalytically inactive mycSseJS151V. Mock-transfected HeLa cells were used as a negative control. Following transfection, HeLa cell lysates were incubated with DPPC liposomes at $\mathrm{pH} 7.4,37{ }^{\circ} \mathrm{C}$ for $2 \mathrm{~h}$. Released FFA were then quantified. HeLa cell lysate containing myc-SseJ led to the release of more than twice as much FFA as lysate from mock-transfected cells or lysate containing myc-SseJS151V $(89.5 \pm 11.7$ nmol FFA versus $34.0 \pm 10.5 \mathrm{nmol}$ FFA and $34.4 \pm 6.8 \mathrm{nmol}$ FFA, respectively). This indicates that SseJ possesses PLA activity, which is dependent on the catalytic $S$ in position 151 in the context of HeLa cell lysate.

\section{Recombinant SseJ displays PLA activity in the presence of HeLa cell extract}

Since we were able to show phospholipase activity of SseJ following its expression in HeLa cells, but not following its purification after expression in E. coli, we hypothesized that it might require a eukaryotic factor for activity. To test this, the activity of GST-SseJ purified from E. coli was monitored in the presence of HeLa cell PNS and DPPC liposomes. Incubation of GST-SseJ with DPPC liposomes together with HeLa cell PNS led to the release of $155.9 \pm 15.8 \mathrm{nmol}$ FFA compared to $69.7 \pm 14.4 \mathrm{nmol}$ and $69.1 \pm 17.3$ nmol FFA detected after incubation with GSTSseJS151V and purified GST, respectively (Fig. 2a). In the absence of PNS, FFA was detected at similar low levels following incubation of DPPC liposomes with GST-SseJ, GST-SseJS151V or GST (Fig. 2a). These results show that a
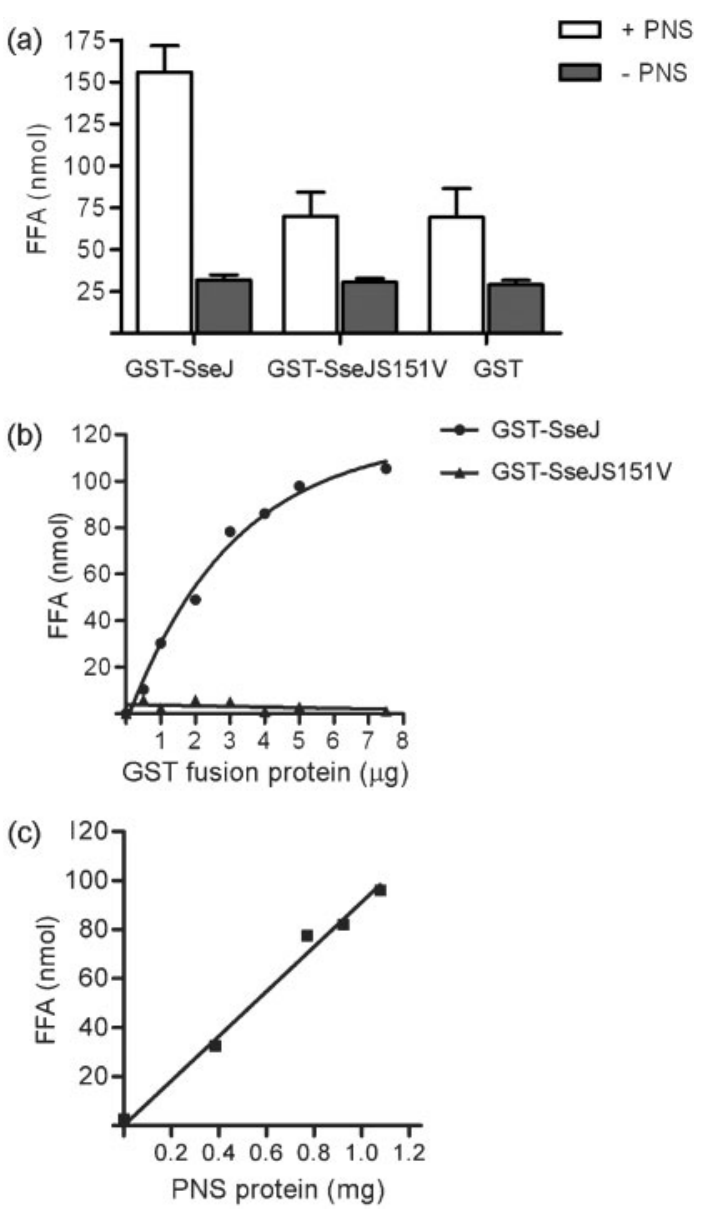

Fig. 2. (a) Phospholipase activity of SseJ requires the presence of a eukaryotic factor. GST-SseJ, GST-SseJS151V or GST was incubated with DPPC liposomes in the presence or absence of HeLa cell PNS for $2 \mathrm{~h}$ at $37^{\circ} \mathrm{C}, \mathrm{pH} 7.4$, before released FFA were quantified. Data represent mean \pm SD derived from three independent experiments performed in triplicate. (b) Phospholipase activity is dependent on SseJ concentration, but limited by the amount of activator. A fixed amount of HeLa cell extract $(0.8 \mathrm{mg}$ protein) was incubated with 1-7.5 $\mu \mathrm{g}$ GST-SseJ (๑), GSTSseJS151V $(\boldsymbol{\Delta})$ or GST for $2 \mathrm{~h}$ at $37{ }^{\circ} \mathrm{C}, \mathrm{pH} 7.4$, before FFA were quantified. Values of FFA following incubation with GST were subtracted from values obtained by incubation of DPPC with equivalent amounts of GST-SseJ or GST-SseJS151V. These data represent the mean derived from two independent experiments performed in triplicate. (c) Phospholipase activity as a function of PNS protein amounts. GST-SseJ $(5 \mu \mathrm{g})(\boldsymbol{\square})$ or GST was incubated with a range of concentrations of HeLa cell PNS from 0 to $1.1 \mathrm{mg}$ protein at $\mathrm{pH}$ 7.4. Released FFA were quantified after $2 \mathrm{~h}$ incubation at $37{ }^{\circ} \mathrm{C}$. Values obtained with GST alone were subtracted from values obtained with GST-SseJ. These data represent the mean derived from two independent experiments performed in triplicate.

factor present in HeLa cell extract is required for PLA activity of SseJ. Incubation of increasing amounts of GSTSseJ with a fixed amount of DPPC liposomes and a fixed 
amount of HeLa cell extract led to an increase in the amount of released FFA up to approximately $5 \mu \mathrm{g}$ GSTSseJ, after which production of FFA plateaued (Fig. 2b). To determine whether the substrate concentration or activating factors were limiting under these conditions, $5 \mu \mathrm{g}$ GST-SseJ and DPPC liposomes were incubated with an increasing amount of eukaryotic cell extract, which led to a linear increase in released FFA (Fig. 2c). This shows that HeLa cell-derived factor(s) limit the reaction under the assay conditions used.

\section{SseJ does not display lysophospholipase activity}

To analyse whether SseJ hydrolyses lysophospholipids, GST-SseJ, GST-SseJS151V or GST was incubated with 1MPLPC micelles at $37{ }^{\circ} \mathrm{C}$, pH 7.4 for $2 \mathrm{~h}$ in the presence of HeLa cell PNS. In contrast to incubation of GST-SseJ with DPPC liposomes, the amount of FFA after incubation of GST-SseJ with 1-MPLPC micelles did not significantly differ from the amount of FFA detected in the presence of GST-SseJS151V or GST (Fig. 3). Therefore, SseJ does not exhibit lysophospholipase activity at $\mathrm{pH} 7.4$ in the presence of HeLa cell PNS using 1-MPLPC micelles as a substrate.

\section{HeLa cell extract-activated SseJ displays GCAT activity}

To test whether SseJ can carry out acyl transfer in the presence of eukaryotic activator, GST-SseJ, GSTSseJS151V or GST was incubated in the presence of HeLa cell PNS with liposomes comprising an equimolar mix of DPPC and partially ${ }^{3} \mathrm{H}$-labelled cholesterol. The formation of ${ }^{3} \mathrm{H}$-labelled CE was measured after lipid extraction and separation via TLC. In the presence of GST-SseJ and HeLa cell PNS, $58214.8 \pm 1162.6$ d.p.m. were detected in the CE fraction, while GST-SseJS151V and GST produced $5543.7 \pm 1418.5$ d.p.m. $\quad$ and $4011.6 \pm 1710.3$ d.p.m.,

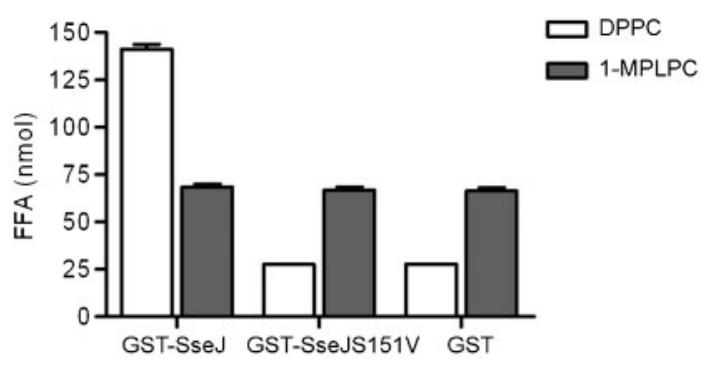

Fig. 3. SseJ does not show lysophospholipase activity in vitro. GST-SseJ, GST-SseJS151V or GST was incubated with DPPC or 1-MPLPC liposomes at $\mathrm{pH} 7.4$ in the presence of HeLa cell lysate for $2 \mathrm{~h}$ at $37^{\circ} \mathrm{C}$ before FFA were quantified. Lysis of DPPC by GST-SseJ served as a positive control. GST and GSTSseJS151V were used as negative controls for both DPPC and 1MPLPC lysis. These results represent the mean \pm SD for each sample (in triplicate), and are representative of two independent experiments. respectively, demonstrating that SseJ possesses GCAT activity in the presence of HeLa cell extract (Fig. 4).

\section{Analysis of the SseJ-activating factor(s)}

HeLa cell extract was required for PLA and GCAT activity of SseJ in vitro. In addition to HeLa cell extract, mouse macrophage RAW 264.7 cell extract contained factor(s) that activated SseJ (Fig. 5a). Soluble extracts of E. coli, S. Typhimurium or Sacc. cerevisiae did not activate SseJ (Fig. $5 \mathrm{a}$ and data not shown). Interestingly, the activity of GSTSseJ was detectable when GST-SseJ was pre-incubated with Sacc. cerevisiae extract at $30^{\circ} \mathrm{C}$ for $1 \mathrm{~h}$ before addition of DPPC liposomes and incubation for $2 \mathrm{~h}$ at $37^{\circ} \mathrm{C}$ (FFA released without pre-incubation, $88.38 \pm 4.84 \mathrm{nmol}$; FFA released after pre-incubation, $132.48 \pm 14.9$ nmol FFA) indicating that Sacc. cerevisiae extract also contained SseJactivating factor(s) (Fig. 5b). Similarly, incubation of GSTSseJ with HeLa cell extract for $1 \mathrm{~h}$ at $37^{\circ} \mathrm{C}$ prior to addition of DPPC liposomes also led to an increase in released FFA compared to FFA released by GST-SseJ that was incubated with activator and substrate simultaneously $(221.50 \pm 24.69 \mathrm{nmol}$ FFA versus $149.48 \pm 22.12 \mathrm{nmol})$ (Fig. 5b). However, pre-incubation of GST-SseJ with E. coli soluble extract did not result in detectable PLA activity of GST-SseJ. We conclude that SseJ was activated by factor(s) present in Sacc. cerevisiae extract only after pre-incubation, suggesting that the concentration of activator might be lower in yeast extract than in HeLa or RAW cell extract.

Several phospholipases are known to require divalent cations, such as $\mathrm{Ca}^{2+}$ (Clark et al., 1991; Dessen et al., 1999; Reynolds et al., 1993). The addition of $10 \mathrm{mM} \mathrm{CaCl}_{2}$,

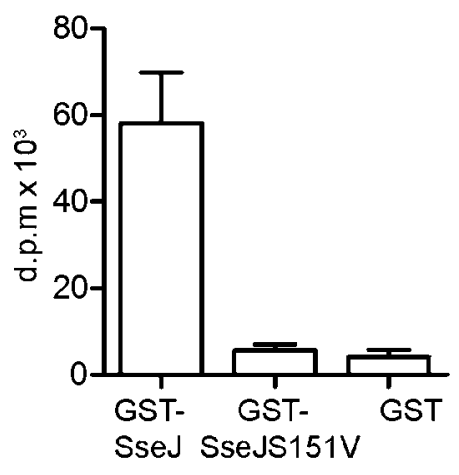

Fig. 4. SseJ displays GCAT activity in the presence of HeLa cell PNS. GST-SseJ, GST-SseJS151V or GST was incubated with DPPC/cholesterol $(1: 1, \mathrm{~mol} / \mathrm{mol})$ liposomes containing $\left[{ }^{3} \mathrm{H}\right]$ cholesterol in the presence of $\mathrm{HeLa}$ cell $\mathrm{PNS}$ at $\mathrm{pH} 7.4$. After $2 \mathrm{~h}$ incubation, lipids were extracted and separated by TLC. Levels of $\left[{ }^{3} \mathrm{H}\right]$ CEs were measured by detection of d.p.m. in the CE fraction. These results represent the mean \pm SD for each sample (in triplicate) and are representative of three independent experiments. 
(a)

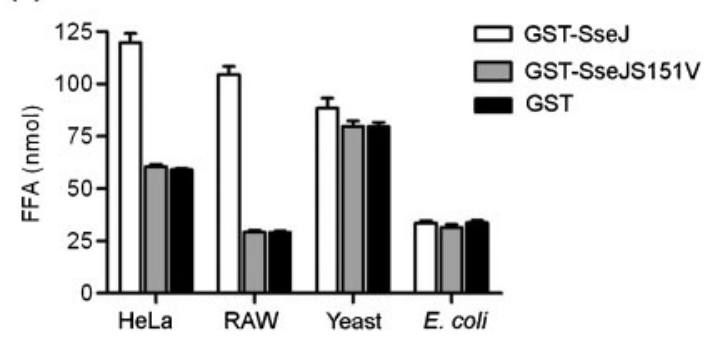

(b)

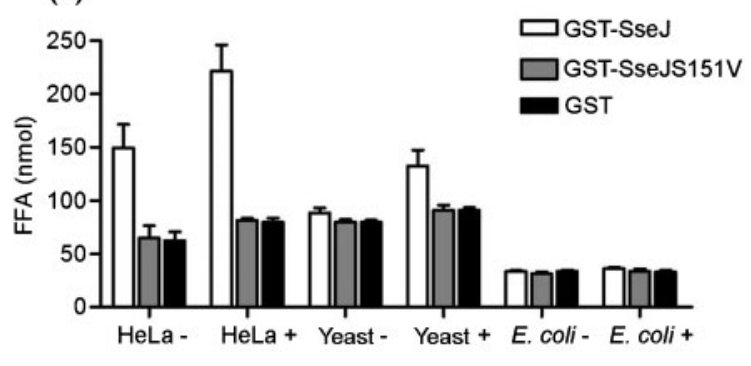

(c)

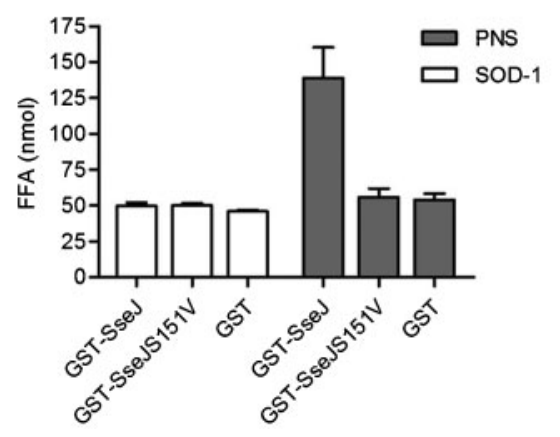

Fig. 5. (a) GST-SseJ, GST-SseJS151V or GST was incubated with DPPC liposomes at $37^{\circ} \mathrm{C}, \mathrm{pH} 7.4$, in the presence of cell lysates extracted from HeLa cells, RAW macrophages, Sacc. cerevisiae (Yeast) or E. coli. Released FFA were quantified after $2 \mathrm{~h}$ incubation. (b) GST-SseJ, GST-SseJS151V or GST was incubated with HeLa cell, E. coli or Sacc. cerevisiae extract for $1 \mathrm{~h}$ at 37 or $30^{\circ} \mathrm{C}$ (Sacc. cerevisiae), respectively, before addition of DPPC liposomes. FFA were quantified after further incubation at $37{ }^{\circ} \mathrm{C}$ for $2 \mathrm{~h}(\mathrm{HeLa}+/$ Yeast $+/$ E. coli +$)$. Released FFA were compared to FFA released in identical assays without preincubation of GST fusion proteins (HeLa-/Yeast-/E. coli-). (c) GST-SseJ, GST-SseJS151V or GST ( $5 \mu \mathrm{g})$ was pre-incubated with $20 \mu \mathrm{g} \mathrm{SOD}-1$ for $1 \mathrm{~h}$ at $37^{\circ} \mathrm{C}$ before addition of DPPC. In a final volume of $200 \mu \mathrm{l}$, FFA were quantified after further incubation for $2 \mathrm{~h}$ at $37^{\circ} \mathrm{C}$. Results shown in $(\mathrm{a}-\mathrm{C})$ represent the mean $\pm \mathrm{SD}$ for each sample (in triplicate) and are representative of two independent experiments.

$\mathrm{MgCl}_{2}$ or $\mathrm{ZnCl}_{2}$ did not activate SseJ phospholipase activity in vitro (data not shown). Fractionation of HeLa cell PNS into cytosolic and membrane fractions prior to addition to the assay demonstrated that the activator was mainly retained in the cytosolic fraction (Fig. 6a). Incubating HeLa
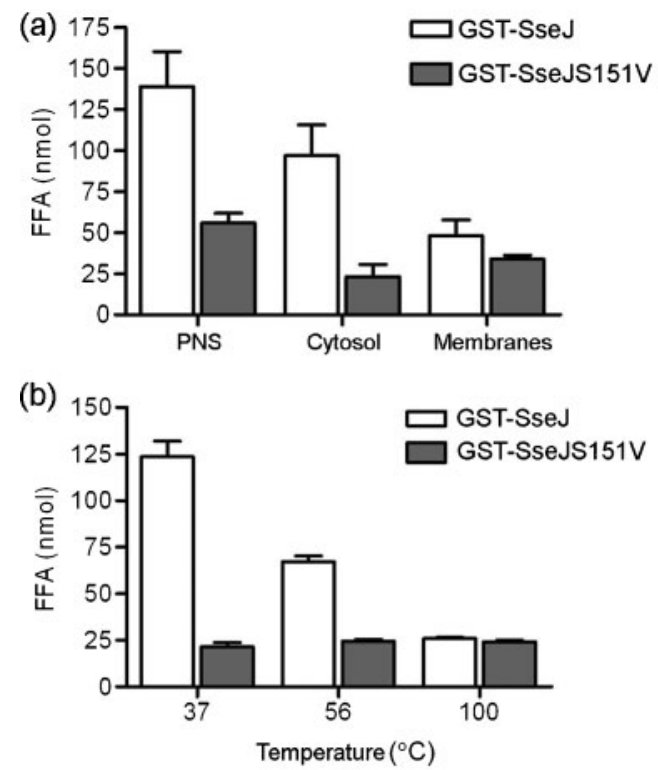

(c)

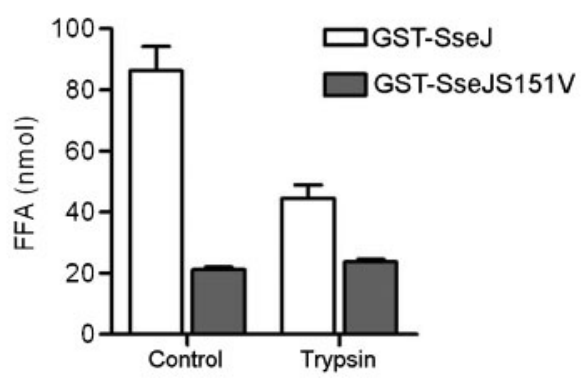

Fig. 6. GST-SseJ, GST-SseJS151V or GST was incubated with DPPC liposomes in the presence of HeLa cell extract. Conditions of cell extract preparation are described below. Data represent the amount of FFA quantified after incubation of GST fusion proteins with DPPC liposomes and cell extract for $2 \mathrm{~h}$ at $37^{\circ} \mathrm{C}$. (a) PNS of HeLa cells was fractionated into cytosolic and membrane fractions by ultracentrifugation. Equivalent proportions of cytosol and membrane fraction were added to the assay. Data shown represent mean $\pm S D$ derived from three independent experiments. (b) HeLa cell cytosol was subjected to $37^{\circ} \mathrm{C}$ for $30 \mathrm{~min}, 56^{\circ} \mathrm{C}$ for $30 \mathrm{~min}$ or $100{ }^{\circ} \mathrm{C}$ for $5 \mathrm{~min}$ before addition to the phospholipase assay. Data represent mean $\pm \mathrm{SD}$ derived from two independent experiments performed in triplicate. (c) HeLa cell cytosol was pre-treated with trypsin for $15 \mathrm{~min}$. The pre-treated cytosol was added to the phospholipase assay after addition of the protease inhibitor aprotinin. In the control, protease inhibitor was added to the cytosolic fraction before addition of trypsin. The results represent the mean \pm SD for each sample (in triplicate) and are representative of three independent experiments.

cell cytosol at $56{ }^{\circ} \mathrm{C}$ decreased its ability to activate SseJ and treatment of cytosol at $100{ }^{\circ} \mathrm{C}$ led to a complete loss of activating ability (Fig. 6b). When cytosol was pre-treated with trypsin before incubation with SseJ, the activating ability of the extract was reduced (Fig. 6c). After subjecting cytosol to size-exclusion filtration with $100 \mathrm{kDa}$ cut-off, the activating factor was retained in the $>100 \mathrm{kDa}$ fraction 
(data not shown). This shows that the activating activity is likely to be proteinaceous and to have a molecular mass over $100 \mathrm{kDa}$ or to be present in a complex with a mass of $>100 \mathrm{kDa}$.

To analyse whether cleavage or other covalent modification of SseJ is responsible for its activation, macrophages were infected with strains of $S$. Typhimurium expressing double HA-tagged SseJ (SseJ-2HA) for $14 \mathrm{~h}$. The electrophoretic mobility of translocated SseJ was compared with SseJ produced by $S$. Typhimurium grown in vitro. No differences in electrophoretic mobility were detected (data not shown).

Superoxide dismutase (SOD-1) is known to be required for the activity of ExoU, a T3SS effector with phospholipase activity expressed by Pseudomonas aeruginosa (Sato et al., 2006). GST-SseJ, GST-SseJS151V or GST was therefore incubated with bovine SOD-1 in excess for $1 \mathrm{~h}$ at $37{ }^{\circ} \mathrm{C}$ prior to addition of DPPC liposomes and further incubation for $2 \mathrm{~h}$ at $37^{\circ} \mathrm{C}, \mathrm{pH} 7.4$; however, no activity of GST-SseJ was detected (Fig. 5c). Therefore, SseJ is likely to be activated by a novel eukaryotic proteinaceous factor.

\section{DISCUSSION}

In this work we have analysed the biochemical activity of SseJ, a Salmonella SPI-2 T3SS effector protein. We found that both the PLA activity and the GCAT activity of SseJ need to be activated by a factor or factors present in eukaryotic cells. We have not yet established the identity of the activator but it is likely to be proteinaceous. There is a formal possibility that a dormant eukaryotic enzyme could be activated (directly or indirectly) by SseJ. This can only be ruled out (or confirmed) conclusively by identification of the activator itself. However, a dormant eukaryotic enzyme seems highly unlikely, given the amino acid sequence similarity between SseJ and other GDSL lipases and GCAT of A. hydrophila. Purified SseJ has been reported to possess deacylase activity on PNPB (Ohlson et al., 2005) and GCAT activity on phosphatidylcholine/cholesterol liposomes (Nawabi et al., 2008). However, we were unable to detect deacylase or GCAT activity of SseJ in the absence of activator using very similar assay conditions to those described elsewhere (Nawabi et al., 2008; Ohlson et al., 2005).

The N-terminal 140 aa of SseJ have similarity to several other SPI-2 effectors and contain a signal for its translocation (Miao \& Miller, 2000). The region of SseJ encompassing amino acids $140-408$, however, is similar to several members of the GDSL lipase family, including GCAT of Aeromonas spp. (26.8\% amino acid identity) (Brumlik \& Buckley, 1996) and PlaC of Legionella pneumophila ( $19.5 \%$ amino acid identity), which also possesses GCAT activity (Banerji et al., 2005; Brumlik \& Buckley, 1996). The GDSL lipase family is characterized by five conserved blocks of amino acids. The first contains the GDSL motif including the catalytic serine, and the third and fifth contain aspartic acid and histidine residues, respectively; together with the serine in block 1 these constitute the catalytic triad (Akoh et al., 2004). The corresponding residues in SseJ (Table 2) are essential for the function of the protein in vivo and for deacylase activity in vitro (Ohlson et al., 2005), and we show in this paper that the predicted catalytic serine in block 1 is essential for both PLA and GCAT activity when stimulated by eukaryotic cell extract. It is not clear why Nawabi et al. (2008) were able to detect GCAT activity in the absence of the activator while we were not. It is possible that differences in methods of enzyme expression and purification, substrate choice (synthetic DPPC versus natural egg phosphatidylcholine) or lipid extraction could have revealed activity in the absence of eukaryotic activator. Notwithstanding this discrepancy, we have clearly demonstrated that the GCAT activity of SseJ is significantly enhanced after exposure to (a) eukaryotic factor(s).

Both GCAT and PlaC need to be activated by proteases (Banerji et al., 2005; Vipond et al., 1998). GCAT activity is potentiated as a result of proteolytic processing by AspA, the major secreted serine protease of Aeromonas salmonicida (Hilton et al., 1990; Vipond et al., 1998). Pro-GCAT $(37 \mathrm{kDa})$ is cleaved at two sites, resulting in three GCAT fragments, two of which are connected via a disulfide bond $(33 \mathrm{kDa})$, so that only a very small fragment of pro-GCAT is lost (Vipond et al., 1998). Both pro- and processed GCAT possess activity in vitro, but only processed GCAT can penetrate lipid monolayers at surface pressures equivalent to those of natural membranes $(>30 \mathrm{mN}$ $\mathrm{m}^{-1}$ ) (Hilton et al., 1990; Hilton \& Buckley, 1991). Activation of $\mathrm{PlaC}$ is dependent on the zinc metalloprotease ProA, although it is not clear whether this effect is direct or indirect (Banerji et al., 2005). Despite these two precedents, it seems unlikely that SseJ is activated by proteolytic cleavage, since several protease inhibitors were added to cell extracts prior to incubation with SseJ and no size difference between intrabacterial and translocated SseJ was detected by Western blotting. Another difference from GCAT and PlaC is that SseJ requires (a) eukaryotic factor(s) for its activity. ExoU, a $P$. aeruginosa T3SS effector protein with PLA2 activity (belonging to the patatin-like lipase family), also requires a eukaryotic activator, which has recently been identified as superoxide dismutase (SOD-1) (Sato et al., 2006). However, the mechanism by which SOD-1 activates ExoU has not yet been elucidated. Purified bovine SOD-1 did not activate SseJ in vitro, and it therefore seems likely that SseJ is activated by a unique mechanism. Attempts to identify the eukaryotic activator(s) are underway and this will provide further insight into the mechanism of activation of SseJ.

It is interesting to consider how the GCAT activity of SseJ might influence the biology of the SCV. SseJ is translocated by the SPI-2 T3SS and localizes to the cytosolic face of the vacuole and Sifs (Freeman et al., 2003), tubular extensions of the SCV which form along microtubules, and which are particularly noticeable in epithelial cells (Garcia-del 
Portillo et al., 1993). Therefore, SseJ is likely to act on phospholipids, present in the SCV membrane and Sifs, transferring acyl chains to cholesterol, which appears by microscopy to be particularly abundant in the SCV membrane (Catron et al., 2002). Although the resolution of light microscopy does not allow one to conclude that cholesterol is present in the SCV membrane itself, immunolabelling of intra-vacuolar Salmonella after exposure of the SCV to saponin (a cholesterol-dependent membrane-permeabilizing reagent) indicates that cholesterol is present in the SCV membrane. The function of SseJ is linked to that of SifA, an SPI-2 T3SS effector whose function has been clarified in recent years. Following translocation and localization to the SCV membrane and Sifs, SifA is prenylated and anchored in the SCV membrane of SCVs and Sifs (Reinicke et al., 2005). SifA binds to SKIP, a host cell protein that prevents the microtubule motor kinesin from being recruited to the SCV. sifA mutants fail to induce the formation of Sifs (Stein et al., 1996) and gradually lose their vacuolar membranes (Beuzon et al., 2000) in a kinesindependent manner (Guignot et al., 2004).

Two intracellular phenotypes have been described that result from mutation of $s s e J$. First, the loss of vacuolar membrane around sifA mutants requires the activity of SseJ (RuizAlbert et al., 2002), and second, deletion of sseJ induces the formation of more Sifs per cell, suggesting that SseJ inhibits Sif formation (Birmingham et al., 2005). Therefore, SseJ appears to oppose the activity of SifA. If the GCAT activity of SseJ in the SCV membrane esterifies cholesterol and removes it from the SCV to lipid droplets (Nawabi et al., 2008), its absence could increase membrane rigidity, facilitating kinesin-mediated rupture of vacuolar membranes around sifA mutant bacteria. Membrane association of prenylated Rab proteins is dependent on the cholesterol content of the membrane (Chen et al., 2008; Lebrand et al., 2002). Hence, by regulating the amount of cholesterol in the SCV membrane, SseJ could control the amount of SifA on the SCV. In the sseJ mutant, more cholesterol could lead to greater incorporation of SifA into the SCV membrane and thereby to an increased level of Sif formation.

The dynamic properties of the SCV membrane are also likely to be altered by SseJ-mediated deacylation of phospholipids, since membrane curvature is affected by the lipid composition of the phospholipid bilayer (McMahon \& Gallop, 2005). Furthermore, GCAT activity could influence host cell signalling pathways by affecting lipid raft composition through its effect on cholesterol and by generating FFA and lysophospholipid.

\section{ACKNOWLEDGEMENTS}

This work was supported by grants from the MRC and Wellcome Trust (UK) to D.W.H. and by a Marie Curie Research Training Network fellowship to N.S. L. The author N.R. was supported by a grant from the European Molecular Biology Organization. Work in A.I.M.'s laboratory was supported by the MRC. We thank Dr Stéphane Méresse for providing plasmid pGEX4T2:: sseJ. 


\section{REFERENCES}

Akoh, C. C., Lee, G. C., Liaw, Y. C., Huang, T. H. \& Shaw, J. F. (2004), GDSL family of serine esterases/lipases. Prog Lipid Res 43, 534-552.

Banerji, S., Bewersdorff, M., Hermes, B., Cianciotto, N. P. \& Flieger, A. (2005). Characterization of the major secreted zinc metalloproteasedependent glycerophospholipid: cholesterol acyltransferase, PlaC, of Legionella pneumophila. Infect Immun 73, 2899-2909.

Beuzon, C. R., Méresse, S., Unsworth, K. E., Ruiz-Albert, J., Garvis, S., Waterman, S. R., Ryder, T. A., Boucrot, E. \& Holden, D. W. (2000). Salmonella maintains the integrity of its intracellular vacuole through the action of SifA. EMBO J 19, 3235-3249.

Birmingham, C. L., Jiang, X., Ohlson, M. B., Miller, S. I. \& Brumell, J. H. (2005). Salmonella-induced filament formation is a dynamic phenotype induced by rapidly replicating Salmonella enterica serovar Typhimurium in epithelial cells. Infect Immun 73, 1204-1208.

Bligh, E. G. \& Dyer, W. J. (1959). A rapid method of total lipid extraction and purification. Can J Biochem Physiol 37, 911-917.

Bonelli, F. S. \& Jonas, A. (1989). Reaction of lecithin cholesterol acyltransferase with water-soluble substrates. J Biol Chem 264, 14723 14728.

Brumlik, M. J. \& Buckley, J. T. (1996). Identification of the catalytic triad of the lipase/acyltransferase from Aeromonas hydrophila. J Bacteriol 178, 2060-2064.

Catron, D. M., Sylvester, M. D., Lange, Y., Kadekoppala, M., Jones, B. D., Monack, D. M., Falkow, S. \& Haldar, K. (2002). The Salmonellacontaining vacuole is a major site of intracellular cholesterol accumulation and recruits the GPI-anchored protein CD55. Cell Microbiol 4, 315-328.

Chen, H., Yang, J., Low, P. S. \& Cheng, J. X. (2008). Cholesterol level regulates endosome motility via Rab proteins. Biophys J 94, 1508-1520.

Cirillo, D. M., Valdivia, R. H., Monack, D. M. \& Falkow, S. (1998). Macrophage-dependent induction of the Salmonella pathogenicity island 2 type III secretion system and its role in intracellular survival. Mol Microbiol 30, 175-188.

Clark, J. D., Lin, L. L., Kriz, R. W., Ramesha, C. S., Sultzman, L. A., Lin, A. Y., Milona, N. \& Knopf, J. L. (1991). A novel arachidonic acidselective cytosolic PLA2 contains a $\mathrm{Ca}^{2+}$-dependent translocation domain with homology to PKC and GAP. Cell 65, 1043-1051.

Dessen, A., Tang, J., Schmidt, H., Stahl, M., Clark, J. D., Seehra, J. \& Somers, W. S. (1999). Crystal structure of human cytosolic phospholipase A2 reveals a novel topology and catalytic mechanism. Cell 97, 349-360.

Flieger, A., Neumeister, B. \& Cianciotto, N. P. (2002) Characterization of the gene encoding the major secreted lysophospholipase A of Legionella pneumophila and its role in detoxification of lysophosphatidylcholine. Infect Immun 70, 6094-6106.

Freeman, J. A., Ohl, M. E. \& Miller, S. I. (2003). The Salmonella enterica serovar Typhimurium translocated effectors SseJ and SifB are targeted to the Salmonella-containing vacuole. Infect Immun 71, 418-427.

Garcia-del Portillo, F., Zwick, M. B., Leung, K. Y. \& Finlay, B. B. (1993). Salmonella induces the formation of filamentous structures containing lysosomal membrane glycoproteins in epithelial cells. Proc Natl Acad Sci U S A 90, 10544-10548.

Guignot, J., Caron, E., Beuzon, C., Bucci, C., Kagan, J., Roy, C. \& Holden, D. W. (2004). Microtubule motors control membrane dynamics of Salmonella-containing vacuoles. J Cell Sci 117, 1033-1045.

Haraga, A., Ohlson, M. B. \& Miller, S. I. (2008). Salmonellae interplay with host cells. Nat Rev Microbiol 6, 53-66.
Hensel, M., Shea, J. E., Gleeson, C., Jones, M. D., Dalton, E. \& Holden, D. W. (1995). Simultaneous identification of bacterial virulence genes by negative selection. Science 269, 400-403.

Hilton, S. \& Buckley, J. T. (1991). Action of a microbial lipase/ acyltransferase on phospholipid monolayers. Biochemistry 30, 6070-6074.

Hilton, S., McCubbin, W. D., Kay, C. M. \& Buckley, J. T. (1990). Purification and spectral study of a microbial fatty acyltransferase: activation by limited proteolysis. Biochemistry 29, 9072-9078.

Lamarche, N., Tapon, N., Stowers, L., Burbelo, P. D., Aspenström, P., Bridges, T., Chant, J. \& Hall, A. (1996). Rac and Cdc42 induce actin polymerization and G1 cell cycle progression independently of p65PAK and the JNK/SAPK MAP kinase cascade. Cell 87, 519-529.

Lebrand, C., Corti, M., Goodson, H., Cosson, P., Cavalli, V., Mayran, N., Faure, J. \& Gruenberg, J. (2002). Late endosome motility depends on lipids via the small GTPase Rab7. EMBO J 21, 1289-1300.

McMahon, H. T. \& Gallop, J. L. (2005). Membrane curvature and mechanisms of dynamic cell membrane remodelling. Nature $\mathbf{4 3 8}$, 590-596.

Miao, E. A. \& Miller, S. I. (2000). A conserved amino acid sequence directing intracellular type III secretion by Salmonella typhimurium. Proc Natl Acad Sci U S A 97, 7539-7544.

Nawabi, P., Catron, D. M. \& Haldar, K. (2008). Esterification of cholesterol by a type III secretion effector during intracellular Salmonella infection. Mol Microbiol 68, 173-185.

Ochman, H., Soncini, F. C., Solomon, F. \& Groisman, E. A. (1996). Identification of a pathogenicity island required for Salmonella survival in host cells. Proc Natl Acad Sci U S A 93, 7800-7804.

Ohlson, M. B., Fluhr, K., Birmingham, C. L., Brumell, J. H. \& Miller, S. I. (2005). SseJ deacylase activity by Salmonella enterica serovar Typhimurium promotes virulence in mice. Infect Immun 73, 6249-6259.

Reinicke, A. T., Hutchinson, J. L., Magee, A. I., Mastroeni, P., Trowsdale, J. \& Kelly, A. P. (2005). A Salmonella typhimurium effector protein SifA is modified by host cell prenylation and $S$-acylation machinery. J Biol Chem 280, 14620-14627.

Reynolds, L. J., Hughes, L. L., Louis, A. I., Kramer, R. M. \& Dennis, E. A. (1993). Metal ion and salt effects on the phospholipase A2, lysophospholipase, and transacylase activities of human cytosolic phospholipase A2. Biochim Biophys Acta 1167, 272-280.

Ruiz-Albert, J., Yu, X. J., Beuzon, C. R., Blakey, A. N., Galyov, E. E. \& Holden, D. W. (2002). Complementary activities of SseJ and SifA regulate dynamics of the Salmonella typhimurium vacuolar membrane. Mol Microbiol 44, 645-661.

Sato, H., Feix, J. B. \& Frank, D. W. (2006). Identification of superoxide dismutase as a cofactor for the Pseudomonas type III toxin, ExoU. Biochemistry 45, 10368-10375.

Stein, M. A., Leung, K. Y., Zwick, M., Garcia-del Portillo, F. \& Finlay, B. B. (1996). Identification of a Salmonella virulence gene required for formation of filamentous structures containing lysosomal membrane glycoproteins within epithelial cells. Mol Microbiol 20, 151-164.

Upton, C. \& Buckley, J. T. (1995). A new family of lipolytic enzymes? Trends Biochem Sci 20, 178-179.

Vipond, R., Bricknell, I. R., Durant, E., Bowden, T. J., Ellis, A. E., Smith, M. \& Maclntyre, S. (1998). Defined deletion mutants demonstrate that the major secreted toxins are not essential for the virulence of Aeromonas salmonicida. Infect Immun 66, 1990-1998.

Waterman, S. R. \& Holden, D. W. (2003). Functions and effectors of the Salmonella pathogenicity island 2 type III secretion system. Cell Microbiol 5, 501-511.

Edited by: M. P. Stevens 